\title{
Insights into the development of Ixodes scapularis: a resource for research on a medically important tick species
}

\author{
Katherine M. Kocan ${ }^{1 *}$, José de la Fuente ${ }^{1,2}$ and Lisa A. Coburn ${ }^{3}$
}

\begin{abstract}
Ticks (Acari: Ixodida) are arthropod ectoparasites dependent on a bloodmeal from a vertebrate host at each developmental stage for completion of their life cycle. This tick feeding cycle impacts animal health by causing damage to hides, secondary infections, immune reactions and diseases caused by transmission of pathogens. The genus Ixodes includes several medically important species that vector diseases, including granulocytic anaplasmosis and Lyme disease. I. scapularis, commonly called the black-legged or deer tick, is a medically-important tick species in North America and therefore was the first tick genome to be sequenced, thus serving as an important resource for tick research. This Primer focuses on the normal developmental cycle and laboratory rearing of $I$. scapularis. Definition of normal morphology, along with a consistent source of laboratory-reared I. scapularis, are fundamental for all aspects of future research, especially the effects of genetic manipulation and the evaluation of tick vaccine efficacy. Recent research important for the advancement of tick research, namely the development of tick cell culture systems for study of ticks and tick-borne pathogens, RNA interference for genetic manipulation of ticks and discovery of candidate antigens for development of tick vaccines, are briefly presented along with areas to target for future research.
\end{abstract}

Keywords: Ixodes scapularis, Ticks, Tick-borne pathogens, Deer tick, Black-legged tick

\section{Why are ticks important?}

Ticks (Acari: Ixodidae) are obligate hematophagous arthropods distributed worldwide. As blood sucking ectoparasites, ticks affect humans and animals by causing allergic reactions, damage to hides, decreased animal production, secondary infections, and by transmission of disease-causing pathogens [1-4]. Ticks have few natural enemies and, despite ongoing control efforts, they continue to be a serious threat to human and animal health. Traditional control methods, based on chemical acaricides, have been only partially successful $[5,6]$, and chemical residues often contaminate the environment and milk and meat products. Importantly, intensive use of acaricides has resulted in the selection of acaricideresistant ticks $[7,8]$, a growing problem affecting cattle production worldwide [9-12] and the high cost of

\footnotetext{
* Correspondence: Katherine.Kocan@okstate.edu

${ }^{1}$ Department of Veterinary Pathobiology, Center for Veterinary Health

Sciences, Oklahoma State University, Stillwater, OK 74078, USA

Full list of author information is available at the end of the article
}

developing new acaricides discourages industry production [12]. New control strategies for ticks are therefore needed, and tick vaccines appear to be a promising and sustainable control approach $[6,8,14-20]$. However, development of new and novel vaccines for control of ticks and tick-borne pathogens will require definition of the molecular basis for tick biology and tick-pathogen interactions for discovery of genes/gene products that could be targeted as candidate vaccine antigens [20].

\section{Why focus research efforts on I. scapularis?}

Tick and tick-borne disease research is a priority because of the increasing global burden of infectious diseases and the one-health approach for developing control strategies for zoonotic diseases. Notably, I. scapularis is a major vector of pathogens in North America that cause diseases in humans and animals, including Borrelia burgdorferi (Lyme disease), Anaplasma phagocytophilum (animal and human granulocytic anaplasmosis, HGA), Babesia microti (rodent and human 
babesiosis), Babesia odocoilei (cervid babesiosis) and Powassan encephalitis virus (PWE) [21]. I. scapularis, commonly called the black-legged or deer tick, is a 3-host tick, and the larva, nymph and adult stages feed on separate hosts [22-27]. I. scapularis is distributed in North America from southeastern Canada to Saskatchewan, along the Atlantic coast and throughout the Eastern half of the U.S. to eastern Texas, Oklahoma and Florida, and a second species, I. pacificus, is found on the west coast. Other Ixodes spp. are common in Europe and other areas of the world. For example, in Europe, I. ricinus transmits A. phagocytophilum, the etiologic agent of tick-borne fever in sheep and other ruminants, and also the emerging disease of humans, HGA $[21,22]$. In the U.S. I. scapularis has a two-year life cycle that varies between geographic regions [23-27]. In the northeastern U.S., nymphs are active during late spring and early summer when they are most likely to transmit pathogens to humans [28], while in the southcentral U.S. I. scapularis is active in the fall and the immature stages feed predominantly on lizards which are not as likely to serve as reservoir hosts for pathogens [24, 25]. In all regions, adult ticks feed on larger mammals, including deer, livestock, carnivores and humans [23-28]. The 2-year I. scapularis life cycle in the northeastern U.S. begins in late summer when larval ticks feed on small mammals and then overwinter and feed as nymphs during the following spring. The adults then feed on large mammals in the fall of the same year [27].

The importance of $I$. scapularis as a vector of pathogens has led to this tick species being a primary focus for research. The selection of I. scapularis as the first tick genome to be fully sequenced contributes to this research focus, and the findings from this genomic information and its analysis serve as a model for research on other Ixodes spp., most notably $I$. ricinus, the medically important tick counterpart in Europe. Current research on I. scapularis includes definition of the genetic basis of tick-pathogen interactions, acaricide resistant genotypes, development of genetic transformation systems, selection of candidate vaccine antigens and development of tick vaccines [20].

Laboratory-reared I. scapularis are essential for research in order to provide a source of uniform, pathogen free ticks. Rickettsial pathogens that infect I. scapularis are transmitted from stage to stage (transstadial transmission) but not by transovarial transmission via eggs. Therefore, subsequent generations of laboratory reared ticks will be pathogen free. While I. scapularis is considerably more difficult to rear, the life cycle can be completed faster in the laboratory (7.5 months as opposed to two years in nature, Fig. 1). The Centralized Tick Rearing Facility, Department of Entomology and Plant Pathology, Oklahoma State University, have devised methods for large-scale production of I. scapularis.

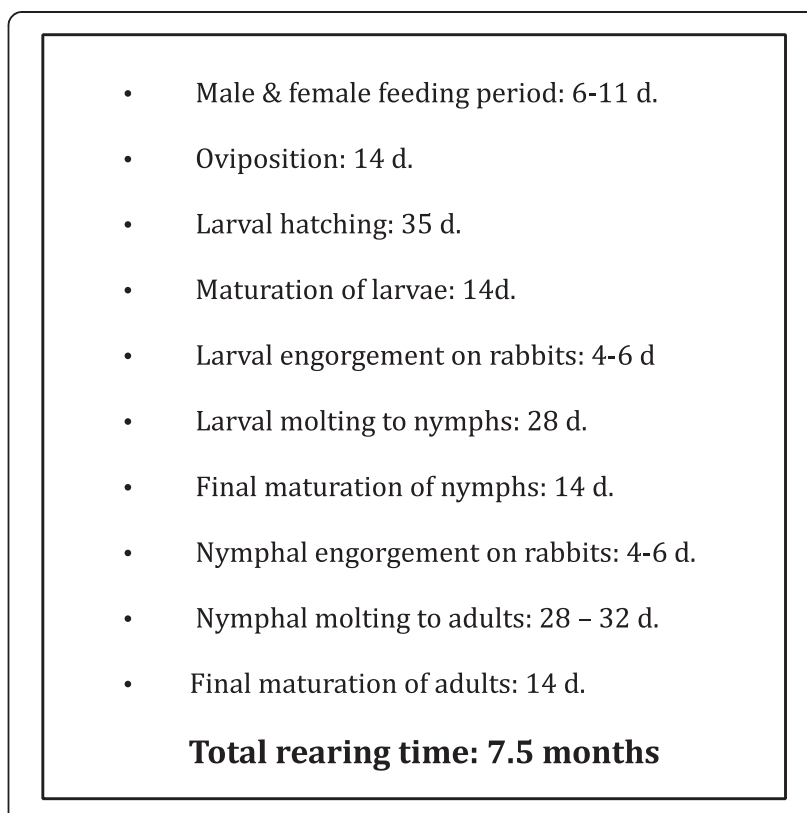

Fig. 1 Time sequence for rearing I. scapularis in the laboratory

Knowledge of the normal development cycle of $I$. scapularis is essential in order to fully assess the effects of experimental and genetic tick manipulations. For this reason, we documented the normal developmental cycle of I. scapularis from mating, oviposition and egg hatching, through the feeding, engorgement and molting of each life stage.

\section{Developmental cycle of $I$. scapularis}

Morphologic details of the I. scapularis developmental stages are presented in the Additional files 1 and 2 in both a poster and video format.

\section{Mating and engorgement}

While many species of male ixodid ticks feed intermittently on the host preceding mating, a bloodmeal is not a prerequisite for I. scapularis mating, and mating can occur off host. Males copulate multiple times with the same or different females, and often stay attached to the female ticks throughout the 6-11 day feeding period. During mating, the male tick inserts the hypostome and chelicerae into the female's genital opening for transfer of the spermatophore, while the palps are splayed to the sides. Successful mating is required for the onset of the rapid stage of engorgement, after which the female drops from the host. In the absence of males, unmated females remain on host and feed slowly for longer periods [23].

\section{Oviposition and emergence of larval ticks}

After female ticks complete mating and the rapid stage of engorgement, they drop off the host. Oviposition then commences and is completed within 14 days. Multicellular 
eggs are expelled from the genital pore on the ventral side of the female and are passed over the capitulum where they are coated with wax extruded from two porous areas on the base of the capitulum. The wax protects the eggs from drying and also loosely binds the eggs together to form an egg mass. Within 35 days the eggs embryonate and prior to hatching the larval body and legs can be seen through the transparent shell. Hatching occurs rapidly as the egg shell ruptures along a suture line. The legs and mouthparts of the newly-hatched larvae are initially transparent, but after 14 days of maturation become sclerotinized. The larvae then quest together in groups for hosts.

\section{Feeding, molting and emergence of nymphs and adults}

Larvae feed 4 days after which they engorge, drop off host and then molt in approximately 28 days to the nymphal stage. The exoskeleton opens on a rupture line at the base of the capitulum. The legs are the last to detach from the exoskeleton. The legs and mouthparts of the newly-molted nymphs are transparent but darken during the 14 day maturation period as sclerotin forms and causes stiffening of the cuticle. After this period, the nymphs quest, attach and feed on the host. Nymphs feed for 4-6 days, after which they drop off the host and molt to the adult (male or female) stage, a process that requires 4-5 weeks. After a maturation time of 14 days, the cuticle stiffens with the formation of sclerotin and the males are able to mate with females either off host or during the feeding cycle on large mammals.

\section{Current advances and future research}

General advances on ticks and tick-borne pathogens and targeted areas for future research are presented because of their implications for ixodid tick species.

\section{Ticks and tick-borne diseases -Three advances made in the last decade \\ Development of tick cell cultures for study of ticks and tick-borne pathogens}

Establishment of continuous tick cell lines was first reported by Varma et al. [31] and subsequently over 40 cell lines are now reported including ones from several tick species [32-35]. Development of these tick cell lines has been an important breakthrough because they have provided a venue for in vitro studies on tick biology and tickpathogen interactions and also have reduced the dependence on animals for research on ticks and tickborne pathogens. Cell lines derived from I. scapularis were the first to be used for propagation of several important tick-borne pathogens, including Anaplasma, Borrelia, Ehrlichia, Rickettsia, and many viruses [34]. Interestingly, Ixodes-derived cell lines were found to support the growth of pathogens for which this tick is not the natural vector, such as $A$. marginale [32, 35]. Tick cell culture has been recently applied to gene silencing and genetic transformation studies, and for characterization of tick-pathogen interactions using omics technologies [20, 34-37].

RNA interference for genetic manipulation of ticks and analysis of the impact gene expression on tick biology and tick-host-pathogen interactions

Tick gene silencing by RNA interference (RNAi), first demonstrated by Aljamali et al. [38], is currently the only means of genetic manipulation of ticks. RNAi has been adapted for use in ticks and tick cell culture [39-41], and has become a valuable tool for functional analyses of tick genes, characterization of the tickpathogen and tick-host interface and for screening for tick protective antigens $[20,41,43]$. RNAi used in combination with transcriptomics and proteomics has also allowed for identification of genes differentially regulated in ticks in response infection with pathogens [36, 39].

\section{Discovery of candidate antigens for development of vaccines against ticks and tick-borne pathogens}

Ticks vaccines, thus far developed for cattle, have been identified as an important component of future control strategies for both ticks and tick-borne pathogens [20]. The tick-protective antigen, BM86, was first used to develop and market the first cattle vaccine for control of Rhipicephalus spp., thus demonstrating the utility of tick vaccines [15-20]. Fundamental toward further development of tick vaccines is the discovery of candidate vaccine antigens $[19,20]$. While new candidate antigens are being tested in cattle [20], the continued search for vaccine antigens has been augmented by the availability of genomic sequence information. The genome of I. scapularis was the first tick genome to be sequenced but will soon be followed by genomes of other important tick species, including that of Rhipicephalus microplus [42], contributing to the discovery of many promising antigens $[20,42,43]$. For example, Subolesin, discovered by expression library immunization and then characterized by RNAi [41, 44] was found to be the ortholog of insect and vertebrate Akirin $[45,46]$, a transcription factor required for NF-kBdependent gene expression and regulation of the innate immune response to pathogen infection [37]. The silencing of Subolesin by RNAi resulted in reduced female weight gains, rendered males sterile, and the failure of females to complete mating and feeding reduced or blocked oviposition [46-48] and also interfered with pathogen infection, development and transmission [49, 50]. Molecular interactions between ticks and pathogens are being defined and will increase the range of candidate vaccine antigens that impact both tick biology and tick pathogen infection and transmission, thus providing the opportunity for development of 'dual target' vaccines that target ticks and tick-borne pathogens [20, 51-59]. 
Ticks and tick-borne diseases -Three areas ripe for research

Analyses of genome sequence and omics data bases and a systems biology approach for discovery of candidate vaccine antigens

Future vaccines will be dependent on inclusion of key molecules important for tick biology and protective mechanisms. A systems biology approach using the large data bases generated from genomic, proteomic, transcriptomic and metabolomic analyses provides the opportunity to comprehensively define the molecular biology of the tick-host cell interface $[20,42,60]$. These data can then be a resource for discovery of a new and expanded generation of biomarkers and candidate vaccine antigens [35]. In addition, when sequences of multiple tick genomes become available, comparative studies across tick species can be conducted toward development of both species-specific vaccines and those crossprotective among multiple tick species. However, while these data bases are presently becoming a valuable resource, limitations in genome sequence information, assembly and annotation provide challenges for future research involving the comprehensive characterization of the molecular events at the tick-pathogen interface [20]. Design of experiments combining tick transcriptomics and proteomics will be dependent on integration of these large datasets for assessing global transcriptome and proteome changes of specific pathways, such as immune response and apoptosis required for pathogen infection and transmission by ticks [49-51].

\section{Development of dual target vaccines for control of ticks and tick-borne pathogens}

Recent results have clearly demonstrated molecular interactions between ticks and the pathogens that they transmit. Candidate tick antigens have been identified that reduce pathogen infection and transmission while also affecting tick infestations [49-59, 61-64]. Therefore, the development of dual target vaccines that reduce both tick infestations and pathogen infection and transmission appears to be an achievable goal, and the combination of tick- and pathogen-derived antigens should result in development of vaccines for ticks and tick-borne diseases $[5,8,20,55]$.

\section{Characterization of tick microbiomes}

Descriptive characteristics of the tick microbiome, which is the collection of commensal, symbiotic and pathogenic microorganisms that occupy each tick species, were recognized years ago but the ability to fully define and characterize these communities is becoming possible because of rapidly-evolving molecular technologies [65]. The developmental cycles of pathogens are complex and pathogens acquired via the blood meal first must infect gut cells and eventually colonize other tissues, some of which are important for transmission during feeding by subsequent stages. Ticks are also infected with endosymbionts which likely impact tick biology and pathogen infections. The understanding of tick microbiomes and their impact on tick survival and vector competency will enhance the search for candidate vaccine antigens within and among tick species and broadly across arthropod groups [65].

\section{Conclusions}

The genus Ixodes includes several species of ticks that are medically important worldwide. Their populations and the pathogens they transmit are expanding posing increased threat to human and animal health. $I$. scapularis is one of the most medically important ticks in the U.S. and has been the first tick genome to be sequenced, providing an important resource for tick and tick-borne pathogen research. Fundamental for future research is a source of laboratory-reared ticks and an understanding of this tick's normal developmental cycle. In this Primer we detailed the $I$. scapularis developmental cycle, recent advances toward the understanding of I. scapularis biology, its role as a vector of pathogens and vaccines development for control of ticks and tick-borne pathogens and areas to target for future research. As part of integrated control programs, tick vaccines promise to be an effective intervention that will reduce the use of acaricides and the selection of acaricide resistant ticks. Because tick species parasitize several vertebrate hosts and share habitat and hosts, development of vaccines cross protective against multiple tick stages, hosts and pathogens should be possible using genome screening and omics technologies to target relevant biological processes for discovery of novel candidate vaccine antigens.

Ethics

Not application.

\section{Additional files}

Additional file 1: Poster of Ixodes scapularis development. (PDF $2003 \mathrm{~kb}$ )

Additional file 2: Video clip of the development of Ixodes scapularis. (MP4 $36664 \mathrm{~kb})$

Abbreviations

HGA: human granulocytic anaplasmosis; PWE: Powassan encephalitis; RNAi: RNA interference.

Competing interests

The authors declare that they have no competing interests. 


\section{Authors' contributions}

KMK and JF conceived of the Primer focus and outline. LC contributed to the design of the poster, editing of the manuscript and provided ticks for this study from the OSU Tick Rearing Facility. KMK photographed the tick stages and prepared the poster. KMK and JF wrote the manuscript. All authors read and approved of the final manuscript.

\section{Acknowledgements}

We thank members of our laboratories for fruitful discussions.

\section{Funding}

The preparation of this chapter was partially supported by the EU FP7 ANTIGONE project number 278976, and the Walter R. Sitlington Endowed Chair for Food Animal Research to K.M. Kocan.

\section{Author details}

${ }^{1}$ Department of Veterinary Pathobiology, Center for Veterinary Health Sciences, Oklahoma State University, Stillwater, OK 74078, USA. ${ }^{2} \mathrm{SaBio}$ Instituto de Investigación en Recursos Cinegéticos (IREC)-Consejo Superior de Investigaciones Científicas (CSIC)-Universidad de Castilla-La Mancha (UCLM)-Junta de Comunidades de Castilla-La Mancha (JCCM), Ronda de Toledo s/n, 13005 Ciudad Real, Spain. ${ }^{3}$ Department of Entomology and Plant Pathology, Oklahoma State University, Stillwater, OK 74078, USA.

\section{Received: 27 August 2015 Accepted: 23 October 2015}

\section{Published online: 14 November 2015}

\section{References}

1. Sonenshine DE, Roe RM. Overview: Ticks, people and animals. In: Sonenshine DE, Roe RM, editors. Biology of Ticks, vol. 1. NY.: Oxford University Press New York; 2014. p. 3-16.

2. Dennis DT, Piesman JF. Overview of tick-bore infections of humans. In: Goodman JL, Dennis DT, Sonenshine DE, editors. Tick-borne Diseases of Humans. Washington D.C: ASM Press; 2005. p. 3-11.

3. Parola P, Raoult D. Tick-borne bacterial diseases emerging in Europe. Clin Microbiol Infect. 2001;7:80-3. doi:10.1046/j.1469-0691.2001.00200.x.

4. Cabezas-Cruz A, Mateos-Hernández L, Pérez-Cruz M, Valdés J. Fernández de Mera IG, Villar M, de la Fuente J. Regulation of the immune response to a-gal and vector-borne diseases. Trends in Parasitology. 2015;31(10):470-6. doi:10.1016/j.pt.2015.06.016

5. de la Fuente J, Kocan KM, Almazán C, Blouin EF. Targeting the tick-pathogen interface for novel control strategies. Frontiers Biosci. 2008;13:7032-45.

6. de la Fuente J, Kocan KM. Strategies for development of vaccines for control of ixodid tick species. Parasite Immuno. 2006;28:275-83.

7. Graf JF, Gogolewski R, Leach-Bing N, Sabatini GA, Molento MB, Bordin EL, et al. Tick control: an industry point of view. Parasitol. 2004;129:S427-42.

8. de la Fuente J, Kocan KM. Development of Vaccines for Control of Tick Infestations and Interruption of Pathogen Transmission. In: Sonenshine DE, Roe RM, editors. Biology of Ticks, Volume 2. 2nd ed. Oxford, UK: Oxford University Press; 2014. p. 333-52.

9. Rosario-Cruz R, Almazán C, Miller RJ, Dominquez-Garcia DI, Hernandez-Ortiz $\mathrm{R}$, de la Fuente J. Genetic basis and impact of tick acaricide resistance. Front Biosci. 2009;14:2657-65.

10. de León AA P, Teel PD, Auclair AN, Messenger MT, Guerrero FD, Schuster G, et al. Integrated strategy for sustainable cattle fever tick eradication in USA is required to mitigate the impact of global change. Front Physiol. 2012:3:195. doi:10.3389/fphys.2012.00196.

11. Abbas RZ, Zaman MA, Colwell DD, Gilleard J, lqbal Z. Acaricide resistance in cattle ticks and approaches to its management: the state of play. Vet Parasitol. 2014;203:6-20.

12. Coles TB, Dryden MW. Insecticide/acaricide resistance in fleas and ticks infesting dogs and cats. Parasit Vectors. 2014;7:8.

13. Parizi LF, Githaka NW, Logullo C, Konnai S, Masuda A, Ohashi K, et al. The quest for a universal vaccine against ticks: cross-immunity insights. Vet J. 2012:194:158-65.

14. de la Fuente J, Kocan KM. Advances in the identification and characterization of protective antigens for development of recombinant vaccines against tick infestations. Exp Rev Vaccines. 2003;2:583-93.
15. Willadsen P, Kemp DH. Vaccination with 'concealed' antigens for tick control. Parasitol Today. 1988;4:196-8.

16. Willadsen P, McKenna RV, Riding GA. Isolation from the cattle tick, Boophilus microplus, of antigenic material capable of eliciting a protective immunological response in the bovine host. Int J Parasitol. 1988;18:183-89.

17. Willadsen P, Riding GA, McKenna RV, Kemp DH, Tellam RL, Nielsen JN, et al. Immunological control of a parasitic arthropod: identification of a protective antigen from Boophilus microplus. J Immunol. 1989;143:1346-51.

18. Willadsen P. Vaccination against ectoparasites. Parasitol. 2006;133(Suppl):S9-25.

19. Sonenshine DE, Kocan KM, de la Fuente J. Tick control: further thoughts on a research agenda. Trends Parasitol. 2006;22:550-1.

20. de la Fuente J, Contreras M. Tick vaccines: current status and future directions. Expert Rev Vaccines. 2015;14:1367-76.

21. Telford SR, Goethert HK. Emerging and emergent tick-borne infections. In: Bowman AS, Nuttal PA, editors. Ticks: Biology, Disease and Control. Cambridge UK: Cambridge University Press; 2008. p. 344-76.

22. Genomic Resources Development Consortium, Contreras M, de la Fuente J, Estrada-Peña A, Grubhoffer L, Tobes R. Transcriptome sequence divergence between Lyme disease tick vectors, Ixodes scapularis and Ixodes ricinus. Genomic Resources Notes. Mol Ecol Resour. 2014;14:1095. doi:10.1111/17550998.12298.

23. Wilson ML, Spielman A. Seasonal activity of immature Ixodes dammini (Acri: Ixodidae). J Med Ent. 1985:22:408-14.

24. Keirans JE, Hutcheson HJ, Durden LA, Klompen SH. Ixodes (Ixodes) scapularis (Acari: Ixodidae): redescription of all active stages, distribution, hosts, geographical variation, and medical and veterinary importance. J Med Entomol. 1996:33:297-318

25. Oliver Jr JH. Lyme borreliosis in the southern United States: a review. J Parasitol. 1996:82:926-35.

26. Dennis DT, Nekomoto TS, Victor JC, Paul WS, Piesman J. Reported distribution of Ixodes scapularis and Ixodes pacificus (Acari: Ixodidae) in the United States. J Med Entomol. 1998;35:629-38.

27. Piesman J. Ecology of Borrelia burgdorferi sensu lato in North America. In: Gray J, Kahl O, Lane RS, Stanek G, editors. Lyme Borreliosis: Biology, Epidemiology and Control. New York, NY: CAB International; 2002. p. 223-50.

28. Bouchard C, Beauchamp G, Nguon S, Trude L, Milord F, Lindsay LR, et al. Associations between Ixodes scapularis ticks and small mammal hosts in a newly endemic zone in southeastern Canada: implications for Borrelia burgdorferi transmission. Ticks Tick Borne Dis. 2011;2:183-90.

29. Varma MGR, Pudney M, Leake CJ. The establishment of three cell lines from the tick Rhipicephalus appendiculatus (Acari: Ixodidae) and their infection with some arboviruses. J Med Entomol. 1975;11:698-706.

30. Blouin EF, de la Fuente J, Garcia-Garcia JC, Sauer JR, Saliki JT, Kocan KM. Applications of a cell culture system for studying the interaction of Anaplasma marginale with tick cells. An Health Res Rev. 2002;3:57-68.

31. Bell-Sakyi L, Paxton E, Wright P, Sumption K. Immunogenicity of Ehrlichia ruminantium grown in tick cell lines. Exp Appl Acarol. 2002;28:177-85.

32. Bell-Sakyi L, Zweygarth E, Blouin EF, Gould EA, Jongejan F. Tick cell lines: tools for tick and tick-borne disease research. Trends Parasitol. 2007;23:450-57.

33. Munderloh UG, Blouin EF, Kocan KM, Ge NL, Edwards WL, Kurtti TJ. Establishment of the tick (Acari: Ixodidae)-borne cattle pathogen Anaplasma marginale (Rickettsiales: Anaplasmataceae) in tick cell culture. J Med Entomol. 1996:33:656-64.

34. Zivkovic Z, Blouin EF, Manzano-Roman R, Ayoubi P, Almazán C, Naranjo V. Massung. R.F.: Jongejan, F., Kocan, K.M., de la Fuente, J. Anaplasma phagocytophilum and A. marginale elicit different gene expression responses in cultured tick cells. Comp Funct Genomics; 2009. doi:10.1155/ 209/705034.

35. de la Fuente J, Merino O. Vaccinomics, the new road to tick vaccines. Vaccine. 2013:31:5923-29.

36. Kocan KM, Zivkovic Z, Blouin EF, Naranjo V, Almazán C, Mitra R, et al Silencing of genes involved in Anaplasma marginale-tick interactions affects the pathogen developmental cycle in Dermacentor variabilis. BMC Develop Biol. 2009. doi:10.1186/1471-2131X-9-42.

37. Ayllón N, Villar M, Galindo RC, Kocan KM, Šíma R, López JA, et al. Systems biology of tissue-specific response to Anaplasma phagocytophilum reveals differentiated apoptosis in the tick vector Ixodes scapularis. PLOS Genetics. 2015. doi:10.1371/journal.pgen.1005120.

38. Aljamali MN, Bior AD, Sauer JR, Essenberg RC. RNA interference in ticks: a study using histamine binding protein dsRNA in the female tick Amblyomma americanum. Insect Mol Biol. 2003;12:299-305. 
39. de la Fuente J, Kocan KM, Almazán C, Blouin EF. RNA interference for the study and genetic manipulation of ticks. Trends Parasitol. 2007;23:427-33.

40. Kocan KM, Blouin E, de la Fuente J. RNA interference in ticks. JoVE. 2011;47, e2474. doi:10.3791/2474

41. de la Fuente J, Almazán C, Blouin EF, Naranjo V, Kocan KM. RNA interference screening in ticks for identification of protective antigens. Parasitol Res. 2005;96:137-41.

42. Maritz-Olivier C, van Zyl W, Christian SC. A systematic, functional genomics, and reverse vaccinology approach to the identification of vaccine candidates in the cattle tick. Rhipicephalus microplus Ticks Tick-borne Dis. 2012;3:179-87.

43. Maritz-Olivier C, Stutzer C, Frans J, Neitz AWH, Gaspar ARM. Tick antihemostatics: targets for future vaccines and therapeutics. Trends Parasitol. 2007;23:397-406. doi:10.1016/j.pt.2007.07.005.

44. Almazán C, Kocan KM, Bergman DK, Garcia-Garcia JC, Blouin EF, de la Fuente J. Identification of protective antigens for control of Ixodes scapularis infestations using cDNA expression library immunization. Vaccine. 2003;21:1492-501.

45. Naranjo N, Ayllón N, de la Lastra JM P, Galindo RC, Kocan KM, Blouin EF, et al. Reciprocal regulation of NF-kB (Relish) and Subolesin in the tick vector, Ixodes scapularis. PLoS ONE. 2013. doi:10.1371/journal.pone.0065915.

46. de la Fuente J, Almazán C, Blas-Machado U, Naranjo V, Mangold AJ, Blouin $\mathrm{EF}$, et al. The tick protective antigen, 4D8, is a conserved protein involved in modulation of tick infection and reproduction. Vaccine. 2006;24:4082-95.

47. de la Fuente J, Alamazán C, Naranjo V, Blouin EF, Meyer JM, Kocan KM. Autocidal control of ticks by silencing of a single gene by RNA interference. Biochem Biophys Res Com. 2006;344:332-38.

48. Merino O, Almazán C, Canales M, Villar M, Moreno-Cid JA, Estrada-Peña A, et al. Control of Rhipicephalus (Boophilus) microplus infestations by the combination of subolesin vaccination and tick autocidal control after subolesin gene knockdown in ticks fed on cattle. Vaccine. 2011;29:2248-54

49. Merino O, Almazán C, Canales M, Villar M, Moreno-Cid JA, Galindo RC, et al. Targeting the tick protective antigen subolesin reduces vector infestations and pathogen infection by Anaplasma marginale and Babesia bigemina. Vaccine. 2011;29:8575-9.

50. de la Fuente J, Moreno-Cid JA, Canales M, Villar M, de la Lastra JM P, Kocan KM, et al. Targeting arthropod subolesin/akirin for the development of a universal vaccine for the control of vector infestations and pathogen transmission. Vet Parasitol. 2011;181:17-22.

51. de la Fuente J, Kocan KM, Blouin EF, Zivkovic Z, Naranjo V, Kocan KM, et al. Functional genomics and evolution of tick-Anaplasma interactions and vaccine development. Vet Parasitol. 2010;167:175-86. doi:10.1016/ j.vetpar.2009.09.019.

52. Merino M, Antunes S, Mosqueda J, Moreno-Cid JA, de la Lastra JM P, Rosario-Cruz R, et al. Vaccination with proteins involved in tick-pathogen interactions reduces vector infestations and pathogen infection. Vaccine. 2013;31:5889-96. doi:10.1016/j.vaccine.2013.09.037.

53. Hajdusek O, Símá R, Ayllón N, Jalovecká M, Perner J, de la Fuente J, et al. Interaction of the tick immune system with transmitted pathogens. Front Cell Infect Microbiol. 2013;3:26. doi:10.3389/fcimb.2013.00026.

54. de la Fuente J, Blouin EF, Manzano-Roman R, Naranjo V, Almazán C, de la Lastra JM P, et al. Functional genomic studies of tick cells in response to infection with the cattle pathogen, Anaplasma marginale. Genomics. 2007;90:712-22

55. Kocan KM, de la Fuente J, Blouin EF. Advances toward understanding the molecular biology of the Anaplasma-tick interface. Front Biosci. 2008;13:7032-45.

56. Zivkovic Z, Esteves E, Almazán C, Daffre S, Nijhof AM, Kocan KM, et al. Differential expression of genes in salivary glands of male Rhipicephalus (Boophilus) microplus in response to infection with Anaplasma marginale. BMC Genomics. 2010;11:186. doi:10.1186/1471-2164-11-186.

57. Antunes S, Galindo RC, Almazán C, Rudenko N, Golovchenko M, Grubhoffe $L$, et al. Functional genomics studies of Rhipicephalus (Boophilus) annulatus ticks in response to infection with the cattle protozoan parasite, Babesia bigemina. Int J Parasitol. 2012;42:187-95.

58. Antunes S, Merino O, Mosqueda J, Moreno-Cid JA, Bell-Sakyi L, Fragkoudis R, et al. Tick capillary feeding for the study of proteins involved in tickpathogen interactions as potential antigens for the control of tick infestation and pathogen infection. Parasit Vectors. 2014;7:42. doi:10.1186/ 1756-3305-7-42

59. Villar M, Popara M, Bonzo_n-Kulichenko E, Ayllón N, Vázquez J, de la Fuente J. Characterization of the tick-pathogen interface by quantitative proteomics. Ticks Tick Borne Dis. 2012;3:154-8. doi:10.1016/j.ttbdis.2012.02.004.
60. Oberg AL, Kennedy RB, Li P, Ovsyannikova IG, Poland GA. Systems biology approaches to new vaccine development. Curr Opin Immunol. 2011;23:43643. doi:10.1016/j.coi.2011.04.005.

61. Marcelino I, de Almeida AM, Ventosa M, Pruneau L, Meyer DF, Martinez D, et al. Tick-borne diseases in cattle: applications of proteomics to develop new generation vaccines. J Proteomics. 2012;75:4232-50. doi:10.1016/ j.jprot.2012.03.026.

62. Liu XY, de la Fuente J, Cote M, Galindo RC, Moutailler S, Vayssier-Taussat M, et al. IrSP1, a tick serine protease inhibitor involved in tick feeding and Bartonella henselae infection. PLoS Negl Trop Dis. 2014;8:7. doi:10.1371/ journal.pntd.0002993.

63. Hammac GK, Pierle SA, Cheng X, Scoles GA, Brayton KA. Global transcriptional analysis reveals surface remodeling of Anaplasma marginale in the tick vector. Parasit Vectors. 2014;7:193. doi:10.1186/1756-3305-7-193.

64. Gomes-Solecki M. Blocking pathogen transmission at the source: reservoir targeted OspA-based vaccines against Borrelia burgdorferi. Front Cell Infect Microbiol. 2014;4:136.

65. Narasimhan S, Fikrig E. Tick microbiome: the force within. Trends Parasitol. 2015;31:315-23. doi:10.1016/j.pt.2015.03.010.

\section{Submit your next manuscript to BioMed Central and take full advantage of:}

- Convenient online submission

- Thorough peer review

- No space constraints or color figure charges

- Immediate publication on acceptance

- Inclusion in PubMed, CAS, Scopus and Google Scholar

- Research which is freely available for redistribution 